\title{
Development of a Traffic Control System by using Microcontroller based Barricade
}

\author{
Lutfun Nahar Nipa \\ Department of Mechanical Engineering, \\ Rajshahi University of Engineering \& Technology \\ Rajshahi-6204, Bangladesh
}

\begin{abstract}
Traffic jam is one of the major problems in a densely populated mega city like Dhaka whereas its population and number of running vehicles are much more than its capacity. Faulty traffic signaling systems, inadequate manpower, narrow road spaces and overtaking tendency of drivers create pro-longed traffic jams. Due to traffic jam a substantial portion of working hours have to be left on streets which indirectly put adverse impact on economy and unavoidable road accident which results loss of lives. As the number of road users constantly increases, and resources provided by current infrastructures are limited, intelligent traffic control system has become a very important issue. In this paper a microcontroller based Traffic Control System is introduced which will make the drivers bound to follow the traffic rules by controlling traffic system, decreasing the rate of accident, controlling crowd, lowering the tendency of road blocking etc. This plan can be applied in cross road junction which are so busy and the sectors those experience a great traffic load. Important cross road junctions of Bangladesh are Science lab junction; Shahabagh junction; Gazipur Cross junction; Shapla Chottor, Motijhil etc. Moreover this system can be applied in 35 points in Bangladesh in an effective way. In this system steel barrier is used to control traffic system which can be closed or opened by using microcontroller and a definite time period is needed to be set in microcontroller. This process is similar to the traffic light system used in mega city of a country but the main difference is in this system, drivers are bound to maintain the traffic rules. Thus this real-time technique can be able to solve the problem.
\end{abstract}

\section{General Terms}

Main theme of this project is traffic problem and a barricade based on microcontroller to reduce this problem. This is one of the most important highlighted problem in Bangladesh mainly in case of cross road junction. Dhaka is the capital of this country and Dhaka city's traffic system is considered to be one of the most chaotic ones in the world. The residents are compelled to undergo physical stress and suffer financial losses in terms of man-hours lost on working days. The media, both print and electronic, have been constantly highlighting the sufferings of the commuters in Dhaka city because of the nagging traffic problem. [1]

\section{Keywords}

Traffic control barricades; Microcontroller; Cross road junction

\section{INTRODUCTION}

The growth of traffic jam in the road network of large cities in developing countries like Bangladesh is a serious concern in case of urban areas. The traffic jam at the road intersections is most crucial because the performance of intersections affects the overall productivity of the whole road network most significantly. To reduce conflicts and ensure orderly movement of traffic at the intersections, it is a common practice to introduce different types of traffic control devices among which traffic control barricade is one of the most popular and effective controlling tool.

Traffic control barricades are sign \& signal device used to guide and control traffic includes pedestrians, motor drivers. Usually placed adjacent or over or along the cross road junction, highways \& other public areas. Mainly used to warn drivers and pedestrians for guiding in a work zone and to redirect traffic on high speed roads. In case of four way road it is really very much important to control traffic in a manageable way. This research addresses the traffic control problem and hence proposes an intelligent traffic control system by using microcontroller based barricade. In particular, the proposed system senses the presence or absence of cars on each lane and then estimate the time to open each barricade which is programmed by microcontroller[2]. Now a days microcontroller based barricade can control traffic in a autonomous way.

The Traffic density is increasing at an alarming rate in developing countries which call for the need of advance intelligent Traffic control system to replace the Conventional manual and microcontroller based Traffic control system. Experimental system in existence involve microcontroller based barricade system for routing of traffic which might be inefficient in situation like fog, rain and dust etc. The Other Conceptual System which is based on interaction of vehicles and cannot be practically implemented in countries like Bangladesh which badly affected by huge traffic problem. The system proposed here involves localized Traffic routing for each intersection junction based on microcontroller Networks. The proposed system has a central microcontroller at every junction which receives data from control room placed on the Road. All programs is controlled by central programmable microcontroller. The Microcontroller makes use of the proposed programmed algorithm to find ways to manage and regulate traffic in a systematic manner efficiently. The Most commonly used Traffic controlling System in developing countries is the microcontroller based system. This system involves a predefined time interval setting for each junction road at an every junction.[3] The barricades increase the traffic-handling capacity of most intersections. They can work independently on timers, or connect to a microcontroller that operates over several intersections in a control room. In a computerized 


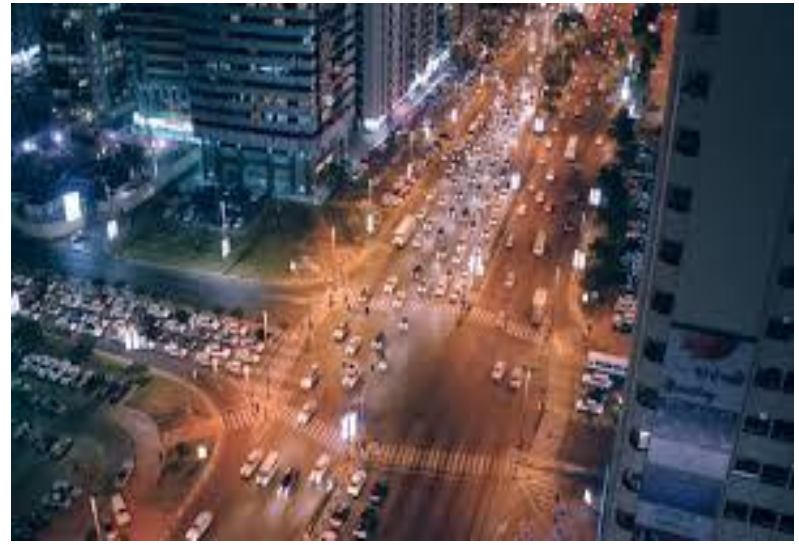

system, traffic barricades are placed at several locationsgenerally in the pavement.[3] Several accident cases on traffic control have been reported in past due to poor control of traffic control at cross roads. In today's world speed is the ultimate word. Everyone is running a rat race and people definitely prefer to spend more time and utilize their energy in doing their respective professional and personal work rather than wasting both their valuable time and energy in commuting on road.[4]

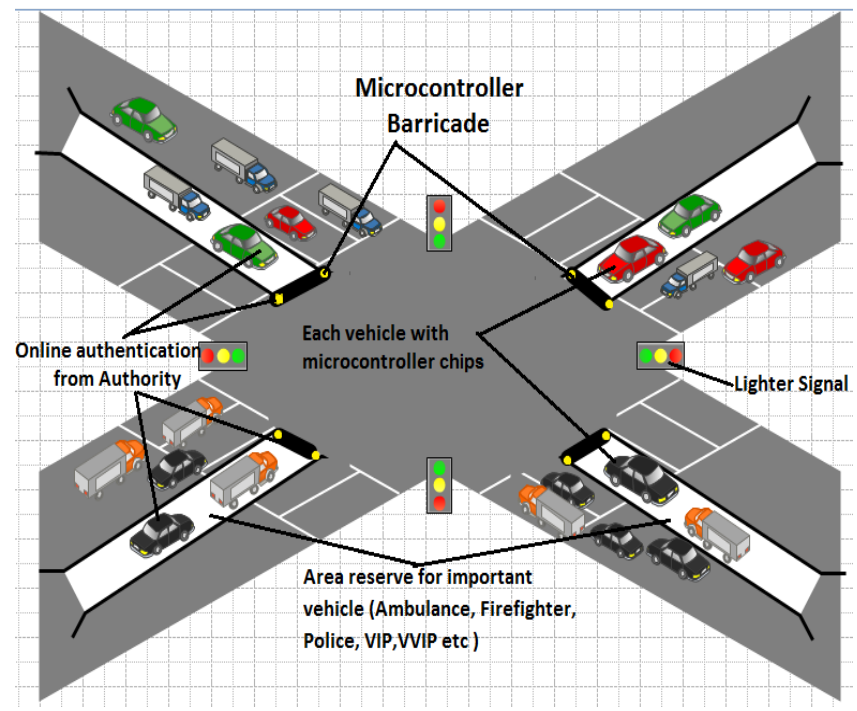

\section{WORKING PRINCIPLE}

A microcontroller can be compared to a small stand-alone computer it is a very powerful device which is capable of executing a series of preprogrammed tasks and interacting with other hardware devices. [5]

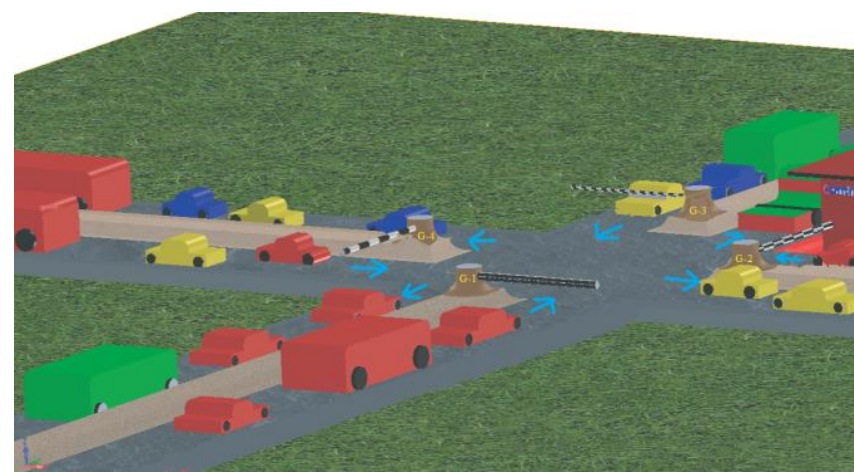

In this system steel barrier is used to control traffic system which can be closed or opened by using microcontroller. A time period is needed to be set in microcontroller according to which these steel barriers will be closed or opened. This process is similar to the traffic light system used in Dhaka city but the main difference is in these systems, drivers are bound to maintain the traffic rules. However most of traffic jams of crowded cities like Dhaka are due to avoiding the traffic rules frequently. However a control room is needed to be used for controlling the whole system because a different kind of order can be needed to input in the microcontroller such as while any VIP car passing through the junction the specific barrier is needed to be opened for a specific period of time.

Consider a cross road junction as shown in above fig where microcontroller based traffic controlling barricade system is being applied.

\section{Process}

Step 1

When the barrier G-1 is open \& the rest barriers such as barrier G-2, G-3, G-4 are closed, only the vehicles from the road belong to barrier G-1 will be allowed to move in their required direction as shown in Fig-1 by the arrows \& the vehicles of other roads belong to barrier G-2, G-3, G-4 are restricted to move.

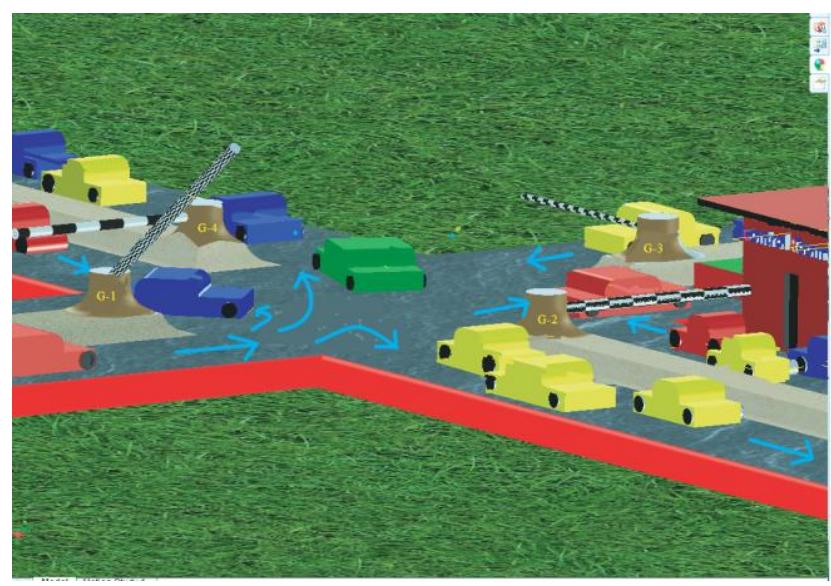

Step 2

After a predetermined time period, controlled by microcontroller, barrier G-2 will open \& barrier G-1, G-3, G-4 will be closed. So only the vehicles from the road belong to barrier G-2 will be moved in their required direction as shown in Fig- 2 by the arrows.

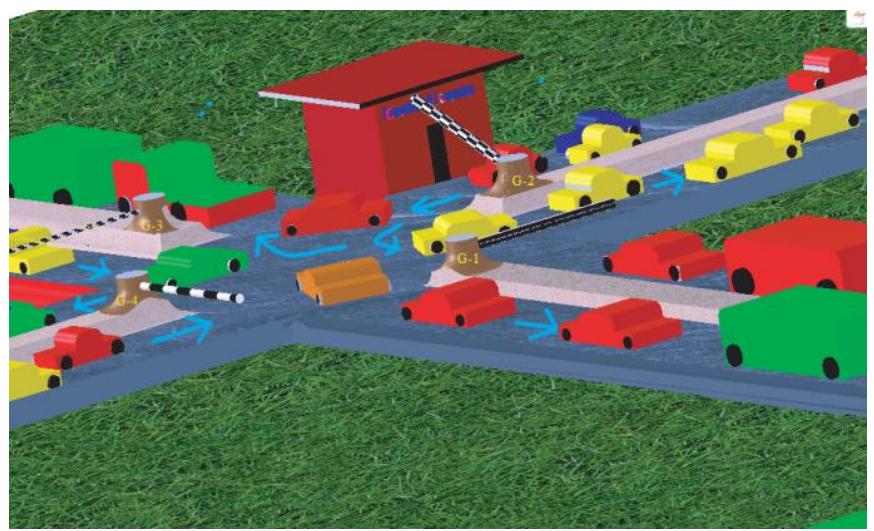




\section{Step 3}

Again after a predetermined fixed period barrier G-3 will be opened but barrier G-1, G-2, G-4 will be closed. So only the vehicles from the road belong to barrier G-3 will be allowed to move in their required direction as shown in Fig-3 by the arrows.

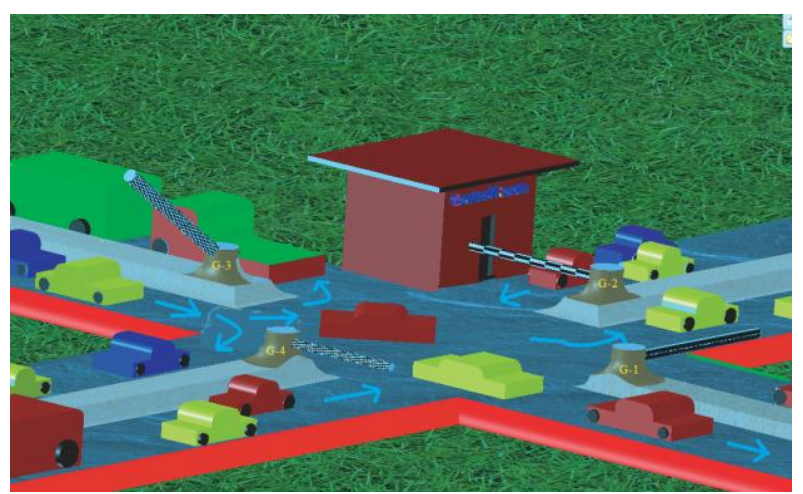

Step 4

At the end on the cycle, barrier G-4 will be opened but barrier G-1, G-2, G-3 will be closed. So only the vehicles from the road belong to barrier G-4 will be allowed to move in their required directions shown in Fig-4 by the arrows.

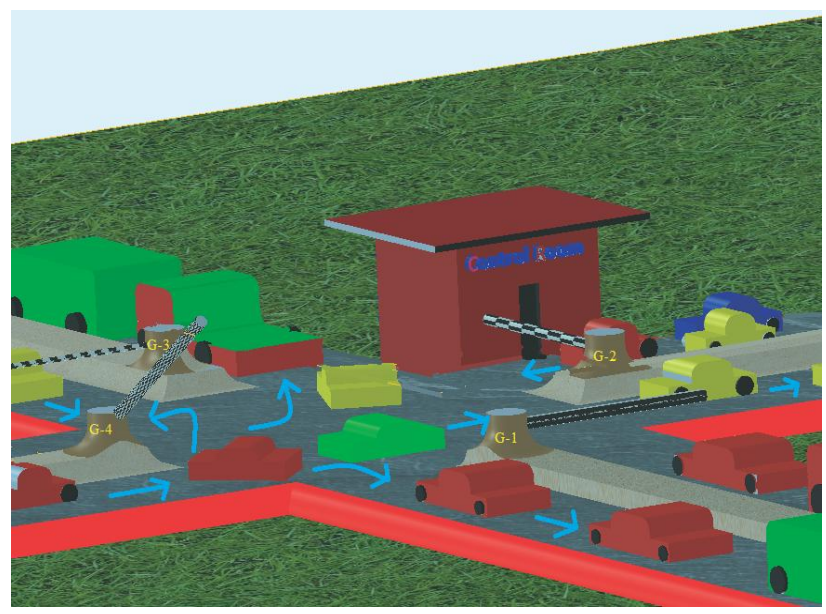

The total process will be repeated continuously until different kinds of requirements

\section{EXPERIMENTAL SET UP}

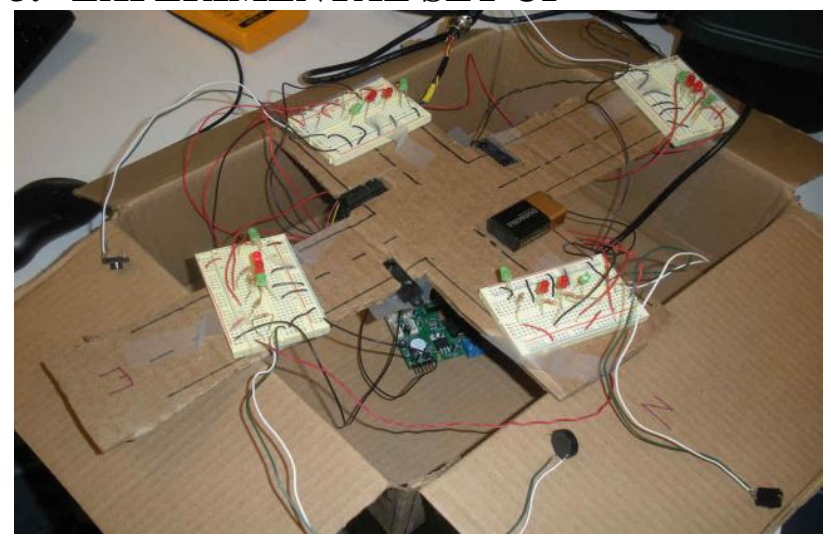

\section{Circuit Diagram}

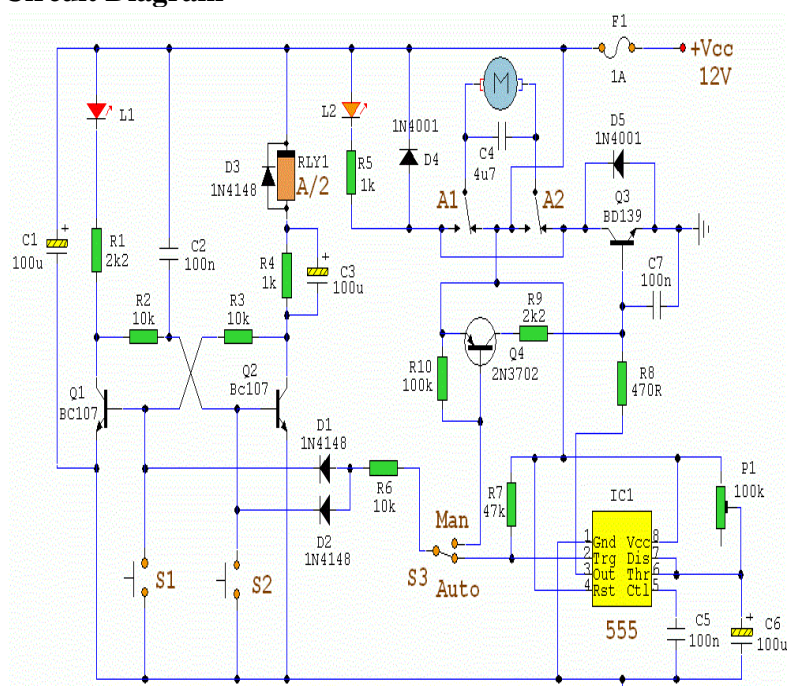

\section{Microcontroller View}

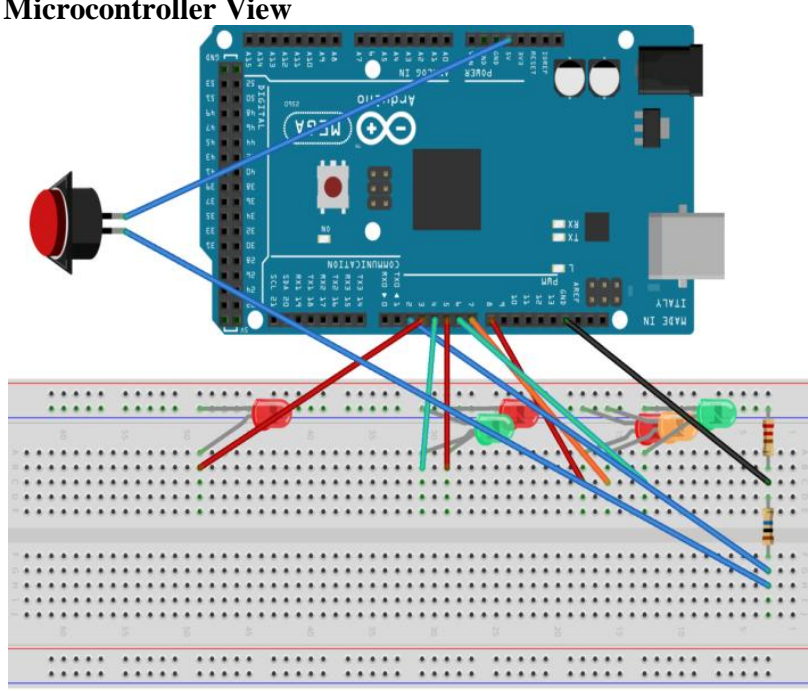

Positive feedback of the project

*This system doesn't need any external technology \& technician

*Related equipment's are easy to maintain \& available.

*Economical for our country.

*Use as an alternate to traffic polices.

*Ensure the safety of pedestrians from accident.

*Maintain the direction of vehicles on the road.

\section{CONCLUSION}

This project is based on a very effective way of optimizing traffic, with redefinition of threshold values for a real time application. This works to control traffic on four way roads according to traffic control barricades which is functioned by microcontroller. This proposed system will be able to build a developed country with less traffic jams and it will also help the emergency vehicle to reach in time to the destination. So, this intelligent system will help us to control traffic in more autonomous way. 


\section{REFERENCES}

[1] Khaled Mahmud1, Khonika Gope1 \& Syed Mustafizur Rahman Chowdhury2 , "Possible Causes \& Solutions of Traffic Jam and their Impact on the Economy of Dhaka City, ; on Journal of Management and Sustainability; Vol. 2, No. 2; 2012 ISSN 1925-4725 E-ISSN 1925-4733 Published by Canadian Center of Science and Education.

[2] Ali M. Abdelrahman, Adil T. Issa, Khalid O. Dafaalla , "Design of an Intelligent Traffic Light Control System ; on Gezira Journal of Engineering and Applied Sciences ; Vol 6, No- 1

[3] Rashid Hussian, Sandhya Sharma,Vinita Sharma, Sandhya Sharma, "WSN Applications: Automated Intelligent Traffic Control System Using Sensors; on
International Journal of Soft Computing and Engineering (IJSCE) ISSN: 2231-2307, Volume-3, Issue-3, July 2013

[4] Ganiyu R. A., Arulogun O. T., Okediran O. O. , “ Development Of A Microcontroller-Based Traffic Light System For Road Intersection Control; on INTERNATIONAL JOURNAL OF SCIENTIFIC \& TECHNOLOGY RESEARCH VOLUME 3, ISSUE 5, May 2014, ISSN 2277-8616

[5] Ahmed Salih Mahdi. Al-Zuhairi*1, "Automatic Railway Gate and Crossing Control based Sensors \& Microcontroller; on International Journal of Computer Trends and Technology (IJCTT) - volume 4 Issue 7-July 2013, ISSN: 2231 